\section{1st PAGES/CLIVAR Working Group Meeting}

IGBP-PAGES and WCRP-CLIVAR recently teamed up to establish the PAGES/CLIVAR Working Group (WG). The impetus for this new WG stems directly from the November 1994 joint IGBP-WCRP workshop (Venice, Italy) on climate variability and predictability, and from the recognition that the new WCRP CLIVAR program needs a firm paleoenvironmental perspective to meet its needs. With the establishment of the PAGES/CLIVAR WG, PAGES (Past Global Changes) becomes one of the first IGBP (International Geosphere-Biosphere Programme) core project to also serve the WCRP (World Climate Research Programme).

$T^{\text {he }}$ he first meeting of the PAGES/CLIVAR WG was just held (October 24-25) in Villefranche-sur-mer, France, and included participants from both the PAGES and CLIVAR research communities.

Building on the recently published 'PAGESCLIVAR Intersection' document (edited by J. C. Duplessy and J. Overpeck, and available from either PAGES, CLIVAR or the Internet WWWeb at http://www.ngdc.noaa.gov/ paleo/reports/clivar.htm), the WG agenda called for a critical review of what paleoclimatic data and methods are available for addressing CLIVAR seasonal- to centennial-scale climate variability issues. This led to discussions focused on specific areas of potential CLIVAR-PAGES interaction, and then to ways to improve the interdisciplinary interaction between the PAGES and CLIVAR communities.

A full report on the WG presentations and recommendations will be published as a joint CLIVAR/PAGES document. The recommendations are summarized here.

As a general preamble, it was decided that PAGES/CLIVAR interactions focus on:

- societially-relevant climate variability (e.g., droughts, floods, storms) and the processes driving this variability, with the recognition that extremes of the 20th century were small relative to those of the preceding centuries and millennia;

- understanding seasonal to century-scale variability as a prerequisite to reliable predictive capability, with the acknowledgment from the paleoclimatic record that decadal to century-scale variability modulates seasonal to interannual variability, and that climate states can abruptly change and persist for decades or longer;

- unraveling key phenomena and mechanisms of climate variability;

- understanding tropical-extratropical interactions.

The intersection of CLIVAR foci and PAGES capabilities led to the identification of several key phenomena and mechanisms for joint study. Each of these phenomena exhibits behavior that can be investigated only with the aid of a paleoclimatic perspective, and only the paleo-record contains empirical information on how these phenomena are affected by changes in climatic forcing. Among these phenomena are specifically:

- ENSO atmosphere-ocean interactions and extratropical linkages;

- Tropical/North Atlantic variability, and interactions between tropical processes and regional drought, the North Atlantic Oscillation, and thermohaline circulation;

- Asian/African monsoon dynamics, linkages with ENSO and extratropical variability;

- shallow meridional ocean circulation and other processes as a mechanisms that link tropical and extratropical climate variability.

It was concluded that many paleoenvironmental tools are available for improving our understanding of these phenomena, with particular interest in insights that can be obtained from coral, ice core, sediments, historical and tree-ring data. These proxies, in conjunction with modeling studies and interdisciplinary interaction between the CLIVAR and PAGES communities, will provide a powerful basis for attacking several specific CLIVAR-relevant objectives. It is recommended that the above-mentioned phenomena and mechanisms be examined with a view to the following specific actions:

\section{Recommended Action 1: a detailed study of climatic variability}

A detailed study of the climatic variability of the last 400 years (globally) and the last 1000 years (where possible). The goal here is to provide the first comprehensive understanding of natural (non-anthropogenically-forced) seasonal to interdecadal variability, and to put the last 100 years in the context of the last 1000. Where possible, the emphasis will be on deriving and using global fields of multiple climatic parameters (e.g., temperature, precipitation, seá-ice), and on the combined use of reconstructed time series of both climate observations and climatic forcing (e.g., SST; volcanic optical depth, solar, trace-gas, and aerosols).
Recommended Action 2:

a comprehensive study of climatic variability

A comprehensive study of climate variability given climatic states and forcing that are significantly different from today. The primary objective acknowledges the fact that global climatic forcing is changing dramatically, and that this means that future climatic variability could be distinctly different from any of the last 150 years. The paleoclimatic record suggests that each of the above-mentioned key phenomena may have been significantly different during the mid-Holocene and Last Glacial Maximum. Thus, specific attention should be given to reconstructing, understanding and modeling climate variability of 6,000 and 21,000 years before present.

\section{Recommended Action 3: a detailed investigation of transient climatic events}

A detailed investigation of major abrupt transient climatic events of the Holocene and Pleistocene. The focus here is on climatic events of the past that, if they were to occur today, would have profound impact on human societies. Past abrupt changes occurred on seasonal to decadal time scales, and provide key insights into how the coupled climate system may respond to altered climate forcing in the future. This recommended PAGES/ CLIVAR action is aimed at avoiding devastating climatic "surprises" in the future, and should be aimed ultimately at developing a predictive ability to simulate major abrupt changes in climatic variability.

The WG discussed linkages to other projects. Most relevant were the PAGES/ CLIVAR ARTS (Annual Records of Tropical Systems) Initiative, and the Paleoclimate Modeling Intercomparison Project (PMIP), both of which focus on meeting the specific PAGES/ CLIVAR priorities listed above. A number of additional PAGES activities and tasks are also of great relevance to PAGES/CLIVAR. Increased coordination with these efforts will be a goal of PAGES/CLIVAR.

The WG meeting ended with a discussion of how interaction between the PAGES and CLIVAR communities could be improved. It is recommended that both focused interdisciplinary science meetings and cross-disciplinary short-courses be held at regular intervals in the future. In many cases, the science meetings should be collaborative with existing PAGES and CLIVAR efforts. Improved interdisciplinary data sharing should also be built upon the existing PAGES data management program at the World Data Center-A for Paleoclimatology, 
with a special PAGES/CLIVAR Internet (WWW) interface for data and information sharing. Lastly, the PAGES/CLIVAR WG calls for greater participation of paleoclimatologists in other CLIVAR activities (i.e., those associated with GOALS, DecCen and ACC).

This summary was provided by PAGES/ CLIVAR WG Co-chairs J-C. Duplessy and J. Overpeck. Additional information, including a list of WG members, can be obtained by con- tacting either PAGES or CLIVAR. A full report of the WG meeting will soon be published (in hard and electronic forms) jointly by PAGES and CLIVAR.

\section{Dr. Jonathan T. Overpeck}

NOAA Paleoclimatology Program

National Geophysical Data Center

325 Broadway E/GC

Boulder, CO 80303 , USA

Phone: 303-497-6172

Fax: 303-497-6513

e-mail: jło@ngdc.noaa.gov

\section{New members at the PAGES Scientific Steering Committee}

The PAGES Scientific Steering Committee welcomed three new members at the start of 1997.

\section{Arrivals...}

Dr Patrick De Deckker, who was born in Belgium, is Reader in the Department of Geology, The Australian National University. He has published widely in taxonomy, ecology, paleoecology, water chemistry, geochemistry, paleolimnology, paleoceanography, paleoclimates, limnology and archaeology.

Dr G.B. Pant is Deputy Director of the Indian Institute of Tropical Meteorology and Head of the Climatology and Hydrometeorology Division. His main academic interests lie within the fields of Atmospheric energetics, Climate and climate change, Paleoclimatology and Climate Modeling.

Dr Dominique Raynaud is Research Director of the CNRS 'Laboratoire de Glaciologie et Géophysique de l'Environment' in the University of Grenoble. He has participated in several, mainly Antarctic, Polar expeditions and published widely on ice core research, the carbon cycle and paleoclimate. He also serves PAGES as the leader of the Antarctic PICE programme.

\section{... and departures}

The pleasure of welcoming new members to the PAGES SSC is always mixed with regret for departing members.

At the end of 1996, Claude Lorius, Eric Odada and Bob Wasson ended their period of service. All made outstanding contributions to the work of PAGES, Claude especially in the area of Antarctic Ice Core-based research for which he has been honoured internationally at the highest level, Eric for his major contribution to PAGES Science in Africa not only through his work with IDEAL, but also through his wide knowledge and contacts, Bob for his commitment both to southern hemisphere matters and to the theme of human impact within the overall framework of Global Change.

stantial contributions to the awarness of global change. Established in 1991, the Revelle Medal recognizes oustanding accomplishments or contributions towards the understanding of the Earth's atmospheric processes including its dynamics, chemistry, and radiation; and towards the role of the atmosphere, atmosphere-ocean coupling, or atmosphere-land coupling in determining the climate, biogeochemical cycles, or other key elements of the climate system.

Edward N. Lorenz was the first recipient of this medal, given not more often than annually. The previous recipients were Edward N. Lorenz (1992), Syukuro Manabe (1993), F. Sherwood Rowland (1994), Wallace S. Broceker (1995), Robert E. Dickinson (1996)

Cindy Jones, who, along with Ulrich Schotterer, takes the credit for the extremely attractive and professional format of our 1995 publications, is now a member of the PAGES staff. Her first task, as Publications Officer has been to produce this Newsletter. 